\title{
Push Pull Mooring dan Pyschological Ownership terhadap Perilaku Beralih Pengguna Instant Messaging
}

\author{
V B Djusmin *1, R T Dirgahayu ${ }^{2}$ \\ ${ }^{1,2}$ Program Studi Teknik Informatika, Program Magister, Universitas Islam Indonesia, \\ Jl. Kaliurang, Yogyakarta, 55584, Indonesia
}

E-mail: vickydjusmin@gmail.com¹, teduh.dirgahayu@uii.ac.id ${ }^{2}$

Masuk: 21 Februari 2019, direvisi: 9 Maret 2019, diterima: 7 Mei 2019

\begin{abstract}
Abstrak. Hasil survei tentang perilaku pengguna Mobile Instant Messaging (MIM) di Indonesia menjelaskan bahwa terjadi arus migrasi pengguna MIM. Perilaku beralih mengakibatkan penurunan pengguna dan profitabilitas layanan pada MIM yang ditinggalkan. Untuk itu diperlukan sebuah pemahaman tentang faktor-faktor yang mempengaruhi individu yang beralih. Penelitian ini bertujuan untuk mengetahui efek pendorong, penarik, serta penambat terhadap niat dan perilaku beralih pengguna MIM. Kepemilikan psikologis sebagai anteseden yang mempengaruhi faktor penghambat. Dalam penelitian ini, Push Pull Mooring digunakan sebagai kerangka untuk mengevaluasi hubungan variabel. Pengujian menggunakan Structural Equation Modelling jenis PLS (SEM-PLS). Hasil penelitian menjelaskan bahwa Dissatisfaction terbukti mendorong individu untuk beralih MIM sedangkan Low System Quality bukan faktor pendorong beralih MIM. Alternative Attractiveness dan Subjective Norm terbukti sebagai penarik pada MIM alternatif. Commitment Affective yang sebelumnya diyakini sebagai faktor penambat beralih, tidak terbukti. Hasil evaluasi ini dapat menjadi acuan penyedia layanan MIM dalam mengembangkan fungsionalitas layanan sebagai upaya mempertahankan pengguna serta menarik pengguna baru.
\end{abstract}

Kata kunci: Mobile Instant Messaging; perilaku beralih; Push Pull Mooring; Psychological Ownership

\begin{abstract}
The survey results on the problems of Mobile Instant Messaging (MIM) users in Indonesia explain what is currently happening to MIM users. The switching behavior drops the user and the service profitability on the abandoned MIM. For this reason, an understanding of the factors influencing individuals is needed. This study aims to determine the driving, pulling, and anchoring effects of the intention and behavior of switching MIM users. Psychological ownership works as an antecedent that affects inhibiting factors. In this study, Push Pull Mooring is used as a consideration to improve variable relationships. The test is conducted using PLS Structural Equation Modeling (SEM-PLS). The results of the study explained that Dissatisfaction was proven to encourage individuals to switch MIM while the Low Quality System was not a driving factor for switching MIM. Alternative Attractiveness and Subjective Norms are proven to be attractive to alternative MIMs. Affective Commitments that previously replaced moving factors, were not proven. The results of this evaluation can be a reference for MIM service providers in developing service functionality to facilitate users and attract new users.
\end{abstract}


Keywords: Mobile Instant Messaging; switching behavior; Push Pull Mooring; Psychological Ownership

\section{Pendahuluan}

Mobile Instant Messaging (MIM) merupakan salah satu aplikasi yang paling banyak tumbuh dan berkembang di seluruh dunia tidak terkecuali di Indonesia. Pertumbuhan MIM diprediksi akan meningkat tiap tahunnya [1]. Dikutip dari Asosiasi Penyelenggara Jasa Internet Indonesia (APJII) tentang penggunaan aplikasi layanan internet pada survei penetrasi dan perilaku pengguna internet di Indonesia tahun 2017, menunjukkan bahwa layanan chatting merupakan layanan yang paling banyak digunakan oleh masyarakat di Indonesia. Sebanyak 89,35\% pengguna menggunakan MIM, selanjutnya disusul pengguna media sosial yaitu $87,13 \%$ dan search engine sebesar $74,84 \%$.

Beberapa penelitian menyebutkan bahwa terdapat berbagai faktor yang menjadi dasar individu menggunakan MIM di antaranya: pengguna dapat berkomunikasi teks dan suara secara real-time [2], [3], fitur yang mudah dan nyaman digunakan, dapat membagikan gambar, video, dan tautan secara langsung, serta memungkinkan melacak status teman mereka di timeline [4], [5]. Selain itu, biaya juga merupakan faktor yang memicu perkembangan penggunaan MIM. Dengan menggunakan MIM biaya yang dikeluarkan menjadi lebih murah [6].

Beragam jenis MIM seperti Whatsapp, Line, BBM, Facebook Messenger, dan Telegram merupakan aplikasi-aplikasi yang populer bagi pengguna MIM di Indonesia. Namun fakta mengungkapkan bahwa popularitas penggunaan MIM tidaklah berada pada posisi yang sama dari tahun ke tahun. Survei yang dilakukan oleh Nielsen bertajuk On Device Meter tahun 2014 yang dikutip dari dailysocial.id menempatkan aplikasi BBM sebagai aplikasi chatting yang banyak digunakan masyarakat Indonesia [7]. Survei tahun 2016 juga menunjukkan bahwa BBM masih dominan diminati. Sebanyak $42,86 \%$ pengguna menggunakan BBM, Whatsapp (27,32\%), Line $(24,71 \%)$, Facebook Messenger (3,47\%), dan Telegram (0,58\%) [8]. Namun pada tahun 2017 terjadi perubahan minat masyarakat terhadap masing-masing aplikasi chatting tersebut. Berdasarkan survei yang dilakukan oleh dailysocial.id pada tahun 2017 terhadap 1.022 responden pada bulan Agustus tentang aplikasi chatting yang digunakan selama tiga bulan terakhir ditemukan bahwa Whatsapp menempati urutan pertama $(61,81 \%)$, kemudian secara berturut-turut diikuti oleh Line $(20,95 \%)$, Blackberry Messenger (10,48\%), Facebook Messenger (5,90\%), Telegram (0,76\%) dan selain aplikasi tersebut sebanyak $0,10 \%$ [9]. Data ini sejalan dengan hasil riset oleh comScore yang menyebutkan bahwa aplikasi Whatsapp merupakan aplikasi chatting terbanyak digunakan di Indonesia.

Berdasarkan data yang dipaparkan di atas, dapat disimpulkan bahwa telah terjadi arus migrasi pengguna MIM. Perilaku pengguna yang beralih dari aplikasi incumbent ke aplikasi alternatif dapat menyebabkan penurunan pengguna dan profitabilitas layanan. Perusahaan penyedia layanan chatting berjuang keras untuk mengembangkan fungsionalitas baru atau mengeluarkan berbagai versi MIM. Berkaitan dengan hal tersebut, diperlukan pemahaman mendalam mengenai faktor-faktor yang mempengaruhi perilaku individu melakukan migrasi dalam konteks penggunaan MIM serta memahami psikologis individu tentang apa yang ingin diperoleh dari aplikasi yang digunakan sehingga dapat bertahan dan menggunakannya secara berkelanjutan. Dengan dasar itu perusahaan penyedia layanan chatting dapat mencari formula strategis untuk menjaga loyalitas pelanggan agar tetap bertahan serta dapat menarik pengguna baru [10], karena pada dasarnya pelanggan merupakan aset yang harus dijaga sebagai upaya untuk menjamin kelangsungan bisnis agar tetap berjalan.

\section{Kerangka Teoritis}

\subsection{Push Pull Mooring}

Untuk mengukur niat beralih individu ke layanan alternatif diperlukan sebuah kerangka kerja untuk menganalisis faktor-faktor yang mempengaruhi individu beralih dari MIM incumbent menuju MIM alternatif. Push Pull Mooring (PPM) merupakan kerangka kerja sebagai pedoman studi migrasi yang menjelaskan mengapa terjadi gerakan manusia dari satu tempat ke tempat lainnya [11]. Kerangka

Djusmin, Dirgahayu (Push Pull Mooring dan Pyschological Ownership terhadap Perilaku Beralih Pengguna Instant Messaging) 
PPM dianggap sebagai paradigma paling dominan dari literatur migrasi. PPM telah diterapkan pada domain pemasaran untuk memperhitungkan perilaku beralih pengguna. Bansal et al. dalam [11] menjelaskan bahwa konsep perilaku migrasi nasional sama dengan fenomena perilaku beralih pengguna dari satu penyedia ke penyedia layanan lainnya. Mereka menemukan model PPM sebagai kerangka yang menyediakan berbagai faktor secara kolektif dari penelitian/literatur beralih layanan. Kerangka kerja PPM yang dikembangkan oleh Bansal pada tahun 2005 ditunjukkan pada Gambar 1. Kerangka kerja tersebut akan digunakan sebagai kerangka kerja untuk mengukur perilaku beralih pengguna dalam konteks MIM.

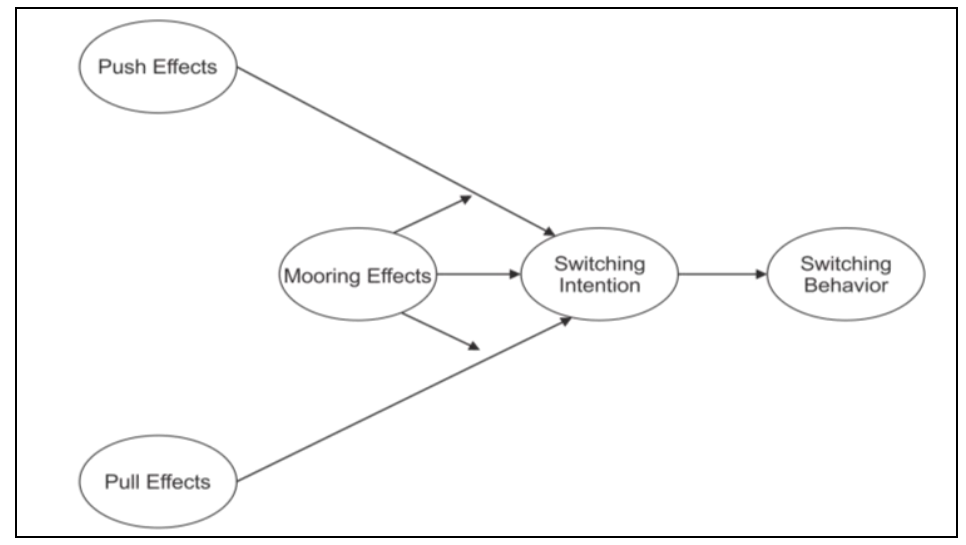

Gambar 1. Kerangka kerja PPM [11]

Berdasarkan Gambar 1, PPM memiliki tiga komponen utama sebagai prediktif dalam menentukan niat beralih pengguna yaitu Push, Pull, dan Mooring. Push Effect berkaitan dengan faktor negatif pada lokasi asli sebagai anteseden yang mendorong individu beralih dari lokasi utama ke alternatif. Efek ini berkaitan erat dengan tingkat kualitas, kepuasaan, kepercayaan, nilai, dan komitmen. Jika indikator tersebut dinilai rendah, maka pengguna akan memutuskan beralih pada layanan alternatif. Pull Effect mengacu pada faktor positif yang ada pada objek tujuan sebagai anteseden yang menarik pengguna/migran untuk menuju lokasi tersebut. Hal ini menggambarkan bahwa ketika pengguna merasakan atribut layanan alternatif lebih baik, mereka lebih mungkin tertarik untuk beralih ke alternatif [12]. Faktor ini merupakan karakteristik positif dari layanan alternatif yang disebut sebagai daya tarik alternatif menurut penelitian tentang perilaku beralih layanan. Selanjutnya adalah Mooring Effect yang merupakan faktor tambahan sebagai fasilitas dalam menghambat keputusan migran menurut konteks pribadi atau sosial.

Penelitian sebelumnya mengungkapkan berbagai faktor yang mempengaruhi migrasi pengguna pada konteks MIM menggunakan kerangka kerja PPM sebagai lensa teoritisnya. Hasil penelitian menjelaskan bahwa faktor pendorong (push) seperti ketidakpuasaan (Dissatisfaction) merupakan faktor yang banyak ditemukan memengaruhi individu untuk beralih menggunakan layanan/aplikasi alternatif [10], [11], [13], [14]. Ketidakpuasan terjadi ketika kinerja produk/layanan yang dipilih tidak dapat memenuhi harapan pengguna. Selain itu, kualitas sistem juga menjadi faktor penting dalam mendorong individu untuk beralih menuju layanan alternatif. Jika kualitas sistem dianggap rendah (Low System Quality), maka pengguna akan mempertimbangkan untuk meninggalkan sistem [15]. Kualitas sistem mengacu pada akuntabilitas, fleksibilitas, serta kemudahan penggunaan sistem.

Faktor penarik (pull) yang memengaruhi niat individu beralih menggunakan aplikasi lain adalah Alternative Attractiveness yang mengacu pada adanya bagian atau layanan yang menarik dari aplikasi alternatif sebagai tujuan melakukan migrasi. Alternative Attractiveness secara signifikan ditemukan memengaruhi niat beralih individu [10], [11], [15]. Faktor penarik lainnya seperti norma subjektif (Subjective Norm), yaitu keyakinan individu untuk terlibat atau tidak pada perilaku tertentu yang dipengaruhi oleh individu lain atau kelompok [16]. Keputusan untuk melakukan adopsi terhadap layanan alternatif mungkin dipengaruhi oleh faktor sosial seperti pilihan pengguna yang signifikan

Djusmin, Dirgahayu (Push Pull Mooring dan Pyschological Ownership terhadap Perilaku Beralih Pengguna Instant Messaging) 
pada suatu layanan [6]. Hou dalam [3] menyebutkan konstruksi tersebut sebagai critical mass yang merupakan konstruksi yang berpengaruh berdasarkan jumlah pengguna di lingkungan sosialnya pada suatu layanan. Norma subjektif telah divalidasi sebagai prediktor yang berpengaruh terhadap keinginan pengguna untuk beralih ke layanan alternatif [11], [17], [18].

Faktor mooring adalah faktor penghambat yang menghalangi niat pengguna melakukan migrasi dari kondisi awal, atau dengan kata lain bahwa faktor yang membuat pengguna lebih memilih bertahan pada layanan yang selama ini digunakan. Pada penelitian ini, sikap komitmen (Commitment Affective) menjadi prediktor utama sebagai faktor mooring yang memengaruhi niat beralih pengguna antar MIM. Commitment Affective didefenisikan sebagai rasa keterikatan terhadap aplikasi [18] atau sikap setia yang ditunjukkan oleh pelanggan. Menjaga komitmen pengguna merupakan tujuan utama penyedia layanan agar pengguna dapat bertahan pada layanan yang digunakan. Komitmen pengguna dapat berpengaruh pada keinginan untuk melanjutkan hubungan menjadi lebih abadi. Berdasarkan penelitian yang ada, maka dapat diidentifikasi bahwa faktor push, pull dan mooring merupakan indikator yang berpengaruh terhadap migrasi individu untuk mengadopsi aplikasi alternatif.

\subsection{Psychological Ownership}

Membangun loyalitas pengguna terhadap aplikasi merupakan bagian yang harus dikerjakan perusahaan agar dapat mempertahankan konsistensinya dalam persaingan pasar. Untuk itu diperlukan pemahaman faktor-faktor yang membuat pengguna memiliki rasa keterikatan terhadap aplikasi agar terbangun perasaaan loyalitas pada aplikasi yang digunakan. Sun et al. mendefinisikan faktor tersebut sebagai Commitment Affective [18]. Komitmen diartikan sebagai keterikatan individu terhadap target tertentu yang menghasilkan kecenderungan untuk mempertahankan hubungan psikologis antara individu dengan target. Peneliti berdalih bahwa komitmen untuk bertahan disebabkan adanya rasa kepemilikan terhadap objek, sehingga penelitian ini akan mencoba mengintegrasikan konstruksi yang dimiliki oleh Teori Psychological Ownership (PO) sebagai anteseden yang berpengaruh terhadap Commitment Affective pada faktor mooring.

Psychological Ownership (PO) merupakan perasaan kepemilikan yang dikembangkan oleh individu terhadap suatu objek/target baik materiil maupun immateriil [19] atau dengan kata lain mengembangkan rasa posesif pada suatu target. Rasa kepemilikan ini akan membawa individu untuk memiliki sifat kepedulian yang tinggi terhadap objek tersebut, rasa tanggungjawab dan mengklaim bahwa "itu milikku" sehingga berdampak pada timbulnya loyalitas terhadap objek. Orang akan mengungkapkan bahwa "itu milikku" ketika rasa kepemilikan sudah ada di dalam dirinya. PO sangat penting terhadap suatu organisasi/perusahaan. Objek yang terbiasa digunakan oleh seorang individu akan berasimilasi ke dalam diri pengguna yang berdampak pada rasa kepemilikian terhadap objek.

Terdapat tiga pengalaman utama yang membuat rasa kepemilikan muncul dalam diri individu terhadap objek yang dimiliki [19], [20], yaitu:

1. Controling the ownership target

Merupakan kontrol yang dapat dilakukan pada objek. Semakin besar kontrol yang diberikan pada objek, maka semakin besar pengalaman psikologis yang dirasakan sebagai bagian dari diri mereka. Kontrol pada objek akan meningkatkan perasaan kepemilikan terhadap objek.

2. Coming to intimately know the target

Hubungan yang hidup/erat dengan objek berdampak pada perasaan kepemilikan individu yang berkembang. Individu akan lebih tertarik kepada sesuatu yang dikenalnya secara akrab. Keakraban berhubungan erat dengan pengetahuan. Semakin banyak informasi dan pengetahuan yang dimiliki individu tentang objek, maka semakin dalam hubungan antara diri dengan objek.

3. Investing the self into the target

Berkaitan dengan keterlibatan diri dalam proses membuat atau mengembangkan objek kepemilikan. Proses tersebut melibatkan investasi waktu, energi, dan bahkan nilai identitas seseorang. Investasi diri individu ke dalam objek menyebabkan diri menjadi satu dengan objek sehingga perasaan kepemilikan terhadap objek menjadi berkembang. 
Psychological Ownership pada penelitian ini dianggap penting untuk lebih menguatkan komitmen pengguna terhadap penggunaan aplikasi atau lebih memberikan rasa loyalitas pengguna terhadap aplikasi. Dampak dari loyalitas tersebut akan membuat pengguna terus menerus bertahan menggunakan aplikasi bahkan secara sukarela memengaruhi individu lain untuk menggunakannya.

Beberapa penelitian mengeksplorasi anteseden dan konsekuensi PO dalam meningkatkan keterlibatan pelanggan dan menumbuhkan loyalitas jangka panjang dalam penggunaan media sosial. Penelitian mengungkapkan bahwa PO berpengaruh positif terhadap loyalitas pengguna [20], [21].

\section{Metodologi Penelitian}

\subsection{Model dan Hipotesis Penelitian}

Model yang dikembangkan diadopsi dari model PPM dan PO . Model digunakan untuk menguji peran Dissatisfaction dan Low System Quality sebagai faktor Push, Alternative Attractiveness, dan Subjective Norm sebagai faktor Pull serta Affective Commitment yang dipengaruhi konstruk PO (Perceived Control, Perceived Familiarity, Self Investment) sebagai faktor Mooring.

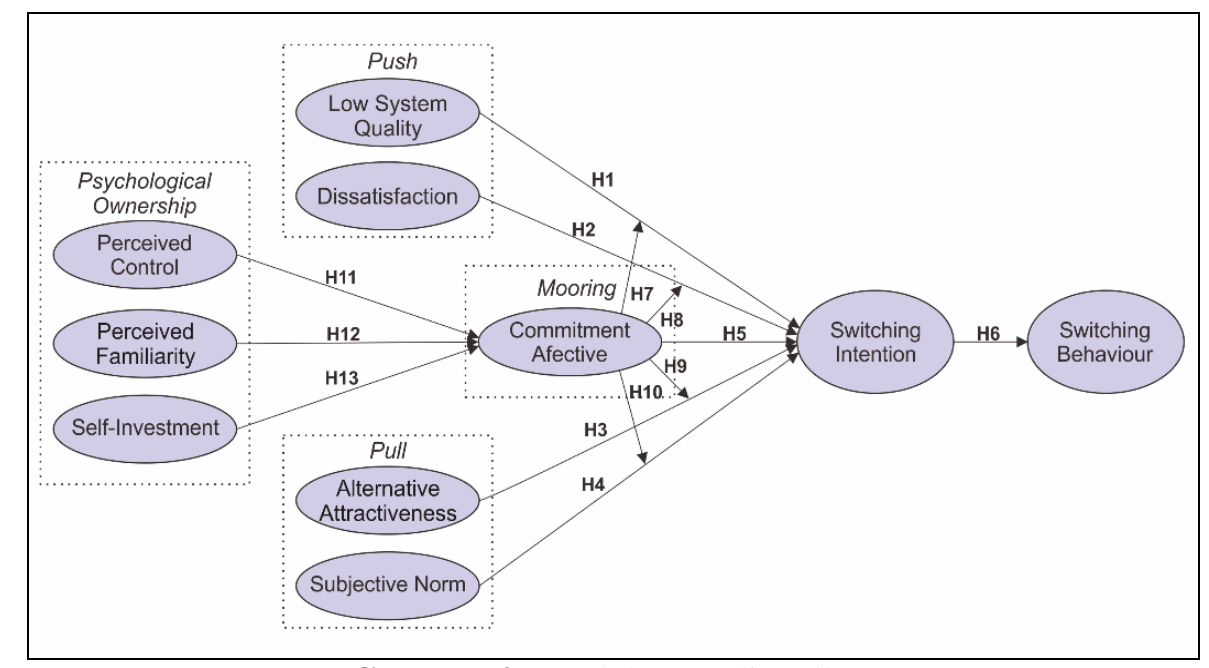

Gambar 2. Model yang diusulkan

Uji Hipotesis yang akan dilakukan pada penelitian ini merujuk pada hubungan antar variabel yang ditunjukkan pada Gambar 2, yaitu:

H1: Low System Quality berpengaruh positif terhadap Switching Intention

H2: Dissatisfaction berpengaruh positif terhadap Switching Intention

H3: Alternative Attractiveness berpengaruh positif terhadap Switching Intention

H4: Subjective Norm berpengaruh positif terhadap Switching Intention

H5: Commitment Affective berpengaruh negatif terhadap Switching Intention

H6: Switching Intention berpengaruh positif terhadap Switching Behavior

H7: Commitment Affective memoderasi hubungan antara Low System Quality dan Switching Intention

H8: Commitment Affective memoderasi hubungan antara Dissatisfaction dan Switching Intention

H9: Commitment Affective memoderasi hubungan antara Alternative Attractiveness dan Switching Intention

H10: Commitment Affective memoderasi hubungan antara Subjective Norm dan Switching Intention

H11: Perceived Control berpengaruh positif terhadap Commitment Affective

H12: Perceived Familiarity berpengaruh positif terhadap Commitment Affective

H13: Self Investment berpengaruh positif terhadap Commitment Affective

Djusmin, Dirgahayu (Push Pull Mooring dan Pyschological Ownership terhadap Perilaku Beralih Pengguna Instant Messaging) 


\subsection{Populasi dan Sampel}

Dalam penelitian ini sumber data atau populasi yang dipilih adalah pengguna MIM yang memiliki pengalaman menggunakan aplikasi Whatsapp, Line, Blackberry Messenger, Facebook Messenger dan Telegram dan dengan waktu penggunaan minimal tiga bulan serta memiliki kriteria usia dari 16 sampai 35 tahun. Rentang usia tersebut dipilih berdasarkan data demografi pengguna terbanyak yang menggunakan aplikasi MIM yang dilansir dari survei dailysocial.id pada tahun 2017. Agar data yang diperoleh mampu mewakili data yang ada pada populasi dalam penelitian ini, maka dilakukan pemilihan responden yang tidak begitu banyak tetapi dapat mewakili populasi dalam penelitian. Jumlah minimum sampel yang akan digunakan pada penelitian ini menggunakan pendekatan Cohen pada tahun 1992 [22]. Dibutuhkan sebanyak 45 sampel berdasarkan model yang dibangun serta 5\% untuk level signifikansi yang diharapkan [23] atau sedikit lebih besar dari pendekatan yang disarankan yaitu 120 sampel. Ukuran tersebut cukup untuk menjawab tujuan penelitian [24].

\section{Metode Pengumpulan Data}

Pengumpulan data dilakukan dengan menggunakan instrumen penelitian berupa kuesioner yang terdiri dari kuesioner online (bit.ly/Mobile_Instant_Messaging) dan paper based. Waktu pengumpulan data dilakukan dalam dua tahap yaitu tahap pertama pada bulan November 2018 dan tahap kedua pada bulan Desember 2018 selama dua minggu. Pengumpulan data pada tahap pertama untuk menguji validitas dan realibilitas instrumen, sedangkan pengumpulan data pada tahap kedua untuk menguji model. URL Kuesioner online disebarkan melalui social media dan grup-grup percakapan, serta membagikan URL langsung ke rekan sejawat untuk disebarkan ke rekan-rekan pengguna aplikasi MIM lainnya. Kuesioner dalam bentuk paper based dibagikan langsung ke responden pengguna aplikasi MIM yang berada sekitar lingkungan peneliti.

Total data yang dikumpulkan berjumlah 228 yang dipilih berdasarkan syarat yang telah ditentukan untuk melakukan evaluasi model. Rincian data demografi ditunjukkan pada Tabel 1.

Tabel 1. Data Demografi Responden

\begin{tabular}{llc}
\hline & Data Demografi & Jumlah \\
\hline Jenis Kelamin & Laki-laki & 75 \\
\multirow{3}{*}{ Usia } & Perempuan & 153 \\
& $17-20$ Tahun & 109 \\
& $21-25$ Tahun & 101 \\
& $26-30$ Tahun & 15 \\
Pendidikan & 31-35 Tahun & 3 \\
& SMA/Sederajat & 180 \\
& D3 & 3 \\
Pekerjaan & S1 & 42 \\
& S2 & 3 \\
& Pelajar/Mahasiswa & 189 \\
& Karyawan Swasta & 29 \\
& Tenaga Pengajar & 3 \\
& IRT & 2 \\
& Lainnya & 5 \\
\hline
\end{tabular}

Berdasarkan data demografi responden pada Tabel 1, dapat disimpulkan bahwa besarnya jumlah responden pada rentang usia 17 sampai 25 tahun disebabkan karena sebagian besar kuesioner disebarkan pada perguruan tinggi dan mayoritas responden berstatus mahasiswa. Hal ini juga berkorelasi dengan tingkat pendidikan responden yang lebih didominasi responden dengan tingkat pendidikan terakhir SMA/Sederajat. Populasi ini dipilih karena survei yang ada menjelaskan bahwa pengguna MIM terbanyak berada pada rentan usia 17 sampai 25 tahun [9].

MIM yang digunakan responden antara lain Whatsapp yaitu sebanyak 199 atau sebesar 87\%, responden pengguna Line sebanyak 19 atau $8 \%$ dari total responden. Selanjutnya Facebook Messenger dan Telegram sebesar 2\% dan BBM sebesar 1\%. Jika dibandingkan dengan data MIM 
yang dahulu digunakan, pengguna beralih dari MIM yang dahulu ke MIM alternatif dan yang paling signifikan adalah perpindahan pengguna dari penggunaan aplikasi Blackberry Messenger ke Whatsapp.

\section{Hasil dan Pembahasan}

Metode analisis yang digunakan untuk melakukan analisis data yaitu dengan metode SEM jenis PLS menggunakan software SmartPLS 3.0.

\subsection{Evaluasi Model Pengukuran (outer model)}

Evaluasi model pada metode PLS dilakukan dengan mengukur validitas dan realibilitas indikator terhadap konstruk pembentuknya. Validitas indikator dilihat berdasarkan validitas konvergen dan validitas diskriminan. Standardized loading factor menggambarkan validitas indikator dengan konstruk pembentuknya. Nilai loading factor yang ideal adalah $\geq 0,7$. Kriteria lain dalam menilai validitas konvergen yaitu dengan melihat nilai Average Variance Extracted (AVE) [25] . Nilai AVE yang dipersyaratkan minimal 0,5. Pengukuran validitas dengan nilai loading factor dan AVE merupakan syarat ideal mengetahui validnya sebuah indikator dalam menguji validitas konvergen pada model pengukuran. Hasil evaluasi model pengukuran ditujukkan pada Tabel 2.

Tabel 2. Evaluasi Model Pengukuran

\begin{tabular}{|c|c|c|c|}
\hline Variabel & (AVE) & Indikator & Loading Factor \\
\hline Alternative & 0.796 & AA1 & 0.892 \\
\hline \multirow[t]{2}{*}{ Attractiveness } & & AA2 & 0.895 \\
\hline & & AA3 & 0.890 \\
\hline Moderasi & 1.000 & $\mathrm{AA} * \mathrm{CA}$ & 1.409 \\
\hline \multirow[t]{3}{*}{ Commitment Affective } & 0.697 & CA1 & 0.829 \\
\hline & & CA2 & 0.878 \\
\hline & & CA3 & 0.795 \\
\hline \multirow[t]{3}{*}{ Dissatisfaction } & 0.657 & DS1 & 0.786 \\
\hline & & $\mathrm{DS} 2$ & 0.751 \\
\hline & & DS3 & 0.889 \\
\hline Moderasi & 1.000 & $\mathrm{DS} * \mathrm{CA}$ & 1.331 \\
\hline \multirow[t]{3}{*}{ Low System Quality } & 0.713 & LSQ1 & 0.709 \\
\hline & & LSQ2 & 0.884 \\
\hline & & LSQ3 & 0.924 \\
\hline Moderasi & 1.000 & $\mathrm{LSQ} * \mathrm{CA}$ & 1.423 \\
\hline \multirow[t]{2}{*}{ Perceived Control } & 0.802 & PC1 & 0.883 \\
\hline & & $\mathrm{PC} 2$ & 0.907 \\
\hline \multirow[t]{3}{*}{ Perceived Familiarity } & 0.737 & PF1 & 0.757 \\
\hline & & PF2 & 0.915 \\
\hline & & PF3 & 0.896 \\
\hline \multirow[t]{3}{*}{ Switching Behavior } & 0.673 & SB1 & 0.798 \\
\hline & & SB2 & 0.805 \\
\hline & & SB3 & 0.856 \\
\hline \multirow[t]{3}{*}{ Self-Investment } & 0.624 & SI1 & 0.787 \\
\hline & & SI2 & 0.746 \\
\hline & & SI3 & 0.834 \\
\hline \multirow[t]{2}{*}{ Subjective Norm } & 0.777 & SN1 & 0.890 \\
\hline & & $\mathrm{SN} 2$ & 0.874 \\
\hline & 1.000 & $\mathrm{SN} * \mathrm{CA}$ & 1.384 \\
\hline \multirow[t]{3}{*}{ Switching Intention } & 0.786 & SWI1 & 0.859 \\
\hline & & SWI2 & 0.909 \\
\hline & & SWI3 & 0.890 \\
\hline
\end{tabular}


Berdasarkan hasil evaluasi pada Tabel 2 dapat dijelaskan bahwa semua indikator memiliki nilai loading factor $\geq 0,7$. Artinya indikator-indikator tersebut valid mengukur konstruknya masing-masing. Nilai AVE pada masing-masing konstruk > 0,5 yang menunjukkan ukuran validitas konvergen yang baik. Pengujian berikutnya adalah evaluasi terhadap realibilitas konstruk yang diukur dengan Cronbach's Alpha dan Composite Realibility (CR). Konstruk harus memiliki nilai $\geq 0,7$. Hasil uji realibilitas ditujukkan pada Tabel 3 .

Tabel 3. Hasil Uji Realibilitas

\begin{tabular}{lcc}
\hline & Cronbach's Alpha & Composite Reliability \\
\hline Alternative Attractiveness (AA) & 0.872 & 0.921 \\
Commitment Affective (CA) & 0.781 & 0.873 \\
CA*AA & 1.000 & 1.000 \\
CA*DS & 1.000 & 1.000 \\
CA*LSQ & 1.000 & 1.000 \\
CA*SN & 1.000 & 1.000 \\
Dissatisfaction (DS) & 0.773 & 0.851 \\
Low System Quality (LSQ) & 0.814 & 0.880 \\
Perceived Control (PC) & 0.753 & 0.890 \\
Perceived Familiarity (PF) & 0.819 & 0.893 \\
Switching Behavior (SB) & 0.758 & 0.860 \\
Self-Investment (SI) & 0.708 & 0.832 \\
Subjective Norm (SN) & 0.714 & 0.875 \\
Switching Intention (SWI) & 0.863 & 0.917 \\
\hline
\end{tabular}

Berdasarkan Tabel 3, nilai Cronbach's Alpha dan Composite Realibility (CR) pada masingmasing konstruk semuanya di atas 0,7 sehingga dapat dinyatakan bahwa semua konstruk memiliki realibilitas yang baik.

\subsection{Evaluasi Model Struktural (inner model)}

Pada tahap ini, evaluasi model struktural (inner model) akan dianalisis dengan melihat signifikansi hubungan antar konstruk yang ditunjukkan dengan nilai t statistic melalui prosedur bootstraping. Nilai $t$ statistic dikatakan valid jika $t$ statistic $\geq 1,96$. Nilai tersebut akan berkolerasi dengan nilai $P$ Value atau nilai signifikansi. Jika nilai $t$ statistic valid maka nilai $P$ Value akan signifikan. Nilai $P$ Value atau signifikansi yang ditetapkan dalam penelitian ini adalah $\leq 0,05$ atau $5 \%$. Pengujian model struktural (inner model) hasil path coefficient juga menjadi pedoman menentukan hipotesis diterima atau ditolak. Hasil pengujian hubungan antar konstruk model struktural ditunjukan pada Tabel 4 .

Tabel 4. Hasil Uji Model Struktural

\begin{tabular}{clcccc}
\hline $\begin{array}{c}\text { Hipotesis } \\
(\text { H) }\end{array}$ & \multicolumn{1}{c}{$\begin{array}{c}\text { Hubungan } \\
\text { Variabel }\end{array}$} & $\begin{array}{c}\text { Original } \\
\text { Sample }(\mathbf{O})\end{array}$ & $\begin{array}{c}\text { T Statistics } \\
(\mid \mathbf{O} / \text { STDEV } \mid)\end{array}$ & P Values & Keterangan \\
\hline H1 & LSQ $\rightarrow$ SWI & -0.053 & 0.694 & 0.488 & Ditolak \\
H2 & DS $\rightarrow$ SWI & 0.150 & 2.183 & 0.029 & Diterima \\
H3 & AA $\rightarrow$ SWI & 0.261 & 3.108 & 0.002 & Diterima \\
H4 & SN $\rightarrow$ SWI & 0.191 & 2.312 & 0.021 & Diterima \\
H5 & CA $\rightarrow$ SWI & 0.249 & 3.704 & 0.000 & Ditolak \\
H6 & SWI $\rightarrow$ SB & 0.690 & 18.114 & 0.000 & Diterima \\
H7 & CA*LSQ $\rightarrow$ SWI & -0.026 & 0.322 & 0.747 & Ditolak \\
H8 & CA*DS $\rightarrow$ SWI & 0.063 & 0.835 & 0.404 & Ditolak \\
H9 & CA*AA $\rightarrow$ SWI & -0.084 & 1.098 & 0.272 & Ditolak \\
H10 & CA*SN $\rightarrow$ SWI & 0.036 & 0.460 & 0.645 & Ditolak \\
H11 & PC $\rightarrow$ CA & 0.442 & 6.281 & 0.000 & Diterima \\
H12 & PF $\rightarrow$ CA & -0.003 & 0.032 & 0.975 & Ditolak \\
H13 & SI $\rightarrow$ CA & 0.215 & 2.307 & 0.021 & Diterima \\
\hline
\end{tabular}


Berdasarkan Tabel 4, hasil analisis data memperlihatkan nilai $P$ Values yang signifikan dan tidak signifikan. Nilai $P$ Value yang memenuhi syarat merupakan acuan menentukan hipotesis mana saja yang diterima. Hasil analisis data menunjukan bahwa Hipotesis H1 yaitu Low System Quality (LSQ) tidak berpengaruh secara signifikan terhadap Switching Intention (SWI). Hasil pengujian hipotesis menyatakan bahwa nilai signifikansi pengaruh LSQ terhadap SWI pada niat beralih antar MIM di atas 0,05 atau $5 \%$ yaitu 0,448 , Sehingga hipotesis $\mathrm{H1}$ ditolak. Dari penelitian yang dilakukan oleh Avus et al. [15] menjelaskan bahwa variabel LSQ merupakan variabel yang mempengaruhi perilaku beralih individu. Namun pada penelitian ini, variabel LSQ tidak ditemukan berpengaruh pada niat beralih individu terkhusus pada penggunaan MIM. Secara umum Individu merasa bahwa aplikasi MIM yang dahulu digunakan juga memiliki kualitas sistem yang baik walaupun pada kenyataannya mereka tetap beralih ke MIM alternatif. Kemungkinan alasan yang membuat mereka beralih karena pengaruh yang kuat memang dilandasi pada sebagian besar orang-orang di sekitarnya sudah beralih ke layanan MIM alternatif sehingga memaksa individu ikut beralih agar tetap dapat berkomunikasi dengan mereka. Ini terbukti dari variabel Subjective Norm (SN) yang signifikan berpengaruh positif terhadap niat beralih individu yang berarti bahwa hipotesis $\mathrm{H} 4$ diterima. Pengaruh ini merupakan faktor yang masuk akal karena saran dari individu lain yang cukup kuat untuk beralih ke layanan MIM alternatif membuat pengguna MIM juga akan berpengaruh untuk beralih. Hal ini terjadi agar hubungan mereka tetap terjaga. Dampak dari pengaruh individu lain atau lingkungan berbanding lurus dengan besarnya keinginan individu untuk beralih ke MIM alternatif. Pengguna akan lebih cenderung beralih jika individu yang berada dalam lingkungannya telah banyak menggunakan MIM alternatif untuk berbagi informasi atau sekedar berkomunikasi. Temuan dalam penelitian ini konsisten dengan penelitianpenelitian terdahulu tentang pengaruh Subjective Norm terhadap niat beralih pengguna [11], [17], [18]. Dari hasil temuan ini dapat menjadi masukan bagi praktisi atau pengembang MIM bahwa faktor norma subjektif sangat kuat mempengaruhi individu untuk beralih ke MIM alternatif. Penyedia layanan dapat melengkapi layanan yang dapat bermanfaat agar pengguna dapat merekrut teman sejawatnya atau keluarga sebagai pengguna baru, serta mempertahankan yang sudah ada.

Faktor Dissatisfaction (DS) signifikan berpengaruh secara positif terhadap niat beralih sehingga Hipotesis H2 diterima. Semakin besar rasa ketidakpuasaan terhadap MIM incumbent maka semakin besar pula niat untuk beralih ke MIM alternatif. Alasan potensial dari ketidakpuasaan tersebut adalah fitur/layanan yang dikembangkan hanya menjadi layanan yang mengganggu dan mengakibatkan kinerja smartphone menjadi lambat. Temuan pada penelitian ini mendukung temuan dari beberapa penelitian terdahulu [10], [11], [13], [14]. Pengaruh ini linear dengan pengaruh Alternative Attractiveness (AA) terhadap niat beralih individu. MIM alternatif yang memiliki daya tarik yang lebih baik dari sisi layanan ataupun fitur akan cenderung membuat individu untuk beralih. Temuan pada penelitian ini menjelaskan bahwa pengaruh AA signifikan dan positif mempengaruhi niat beralih individu dalam konteks penggunaan MIM di Indonesia, sehingga hipotesis H3 diterima. Kedua hipotesis yaitu hipotesis $\mathrm{H} 2$ dan $\mathrm{H} 3$ mengkonfirmasi bahwa proses pengembangan layanan serta fitur perlu diperhatikan. Pengembang perlu mempertimbangkan kebutuhan-kebutuhan pengguna, bukan hanya mengenai jumlah layanan atau fitur yang dikembangkan tetapi diperlukan pemahaman yang jauh tentang fitur atau layanan yang dibutuhkan oleh pengguna, karena pada dasarnya bahwa banyaknya fitur yang dikembangkan dalam sebuah aplikasi tidak menjamin aplikasi dapat survive, yang terpenting adalah apakah fitur tersebut bermanfaat bagi pengguna sehingga tidak hanya dianggap sebagai layanan yang mengganggu dan membuat aplikasi semakin sulit untuk diakses.

Commitment Affective (CA) yang diharapkan sebagai variabel mooring yang dapat menghambat individu untuk beralih ke layanan alternatif ditemukan mempengaruhi secara signifikan dan positif terhadap niat beralih layanan MIM. Dengan kata lain bahwa jika komitmen individu kuat maka keinginan untuk beralih juga semakin tinggi. Sehingga variabel CA yang diharapkan dapat menghambat individu beralih tidak terbukti sehingga hipotesis H5 ditolak. Efek moderasi dari CA terhadap hubungan variabel LSQ, DS (faktor pendorong), SN, AA (faktor penarik) dengan niat beralih (SWI) juga tidak ditemukan berpengaruh sehingga Hipotesis H7, H8, H9, dan H10 ditolak. Tidak berpengaruhnya variabel CA baik sebagai faktor penambat maupun sebagai moderasi kemungkinan terjadi karena sebagian besar responden memang telah beralih ke layanan alternatif sehingga efek

Djusmin, Dirgahayu (Push Pull Mooring dan Pyschological Ownership terhadap Perilaku Beralih Pengguna Instant Messaging) 
mooring tidak berpengaruh lagi. Namun dari hasil temuan dapat disimpulkan bahwa jika individu telah atau sementara mengeksplorasi layanan alternatif yang dapat meningkatkan komitmen individu, maka akan membuat individu semakin kuat untuk beralih secara keseluruhan. Individu akan beralih dari MIM yang dahulu digunakan menuju MIM yang dianggap lebih baik.

Hubungan antara Switching Intention (SWI) dengan Behavior Intention (SB) memiliki korelasi yang kuat. Individu yang memiliki niat beralih akan berpotensi mempengaruhi perilaku beralihnya, hasil temuan menjelaskan hubungan yang signifikan antara SWI dengan SB. Niat beralih berpengaruh positif dan signifikan terhadap perilaku beralih sehingga hipotesis H6 diterima. Temuan ini konsisten dengan beberapa penelitian yang dilakukan sebelumnya [11], [26].

Efek Psychological Ownership (PO) yang ditambahkan ke dalam model PPM sebagai faktor yang mempengaruhi CA berpengaruh positif dan signifikan terkhusus pada variabel Perceived Control (PC) dan Self-Investment (SI) sehingga hipotesis H11 dan H13 diterima. Jika individu memiliki kontrol yang lebih terhadap aplikasi MIM akan meningkatkan rasa komitmen terhadap aplikasi. Begitupun dengan faktor investasi diri terhadap aplikasi yang digunakan. Semakin besar investasi yang diberikan, baik waktu, tenaga serta keterlibatan individu terhadap pengembangan aplikasi maka semakin meningkatkan komitmen terhadap penggunaan aplikasi MIM secara berkelanjutan. Pengaruh ini kontradiksi dengan pengaruh faktor perceived familiarity (PF). Kedekatan atau rasa familiar terhadap penggunaan aplikasi MIM tidak berpengaruh terhadap komitmen individu untuk menggunakan MIM secara berkelanjutan sehingga hipotesis H12 ditolak. Pengguna mungkin merasa bahwa kedekatan dengan MIM tidak cukup untuk membuat individu dapat meningkatkan komitmennya dalam menggunakan MIM. Dalam kasus ini kemungkinan rasa kedekatan (familiarity) akan muncul dengan sendirinya jika individu memiliki kontrol dan investasi yang besar terhadap MIM yang digunakan. Sebagai kesimpulan, berdasarkan model yang dikembangkan, hasil pengaruh hubungan yang dihipotesiskan dalam penelitian ini dapat digambarkan seperti pada Gambar 3.

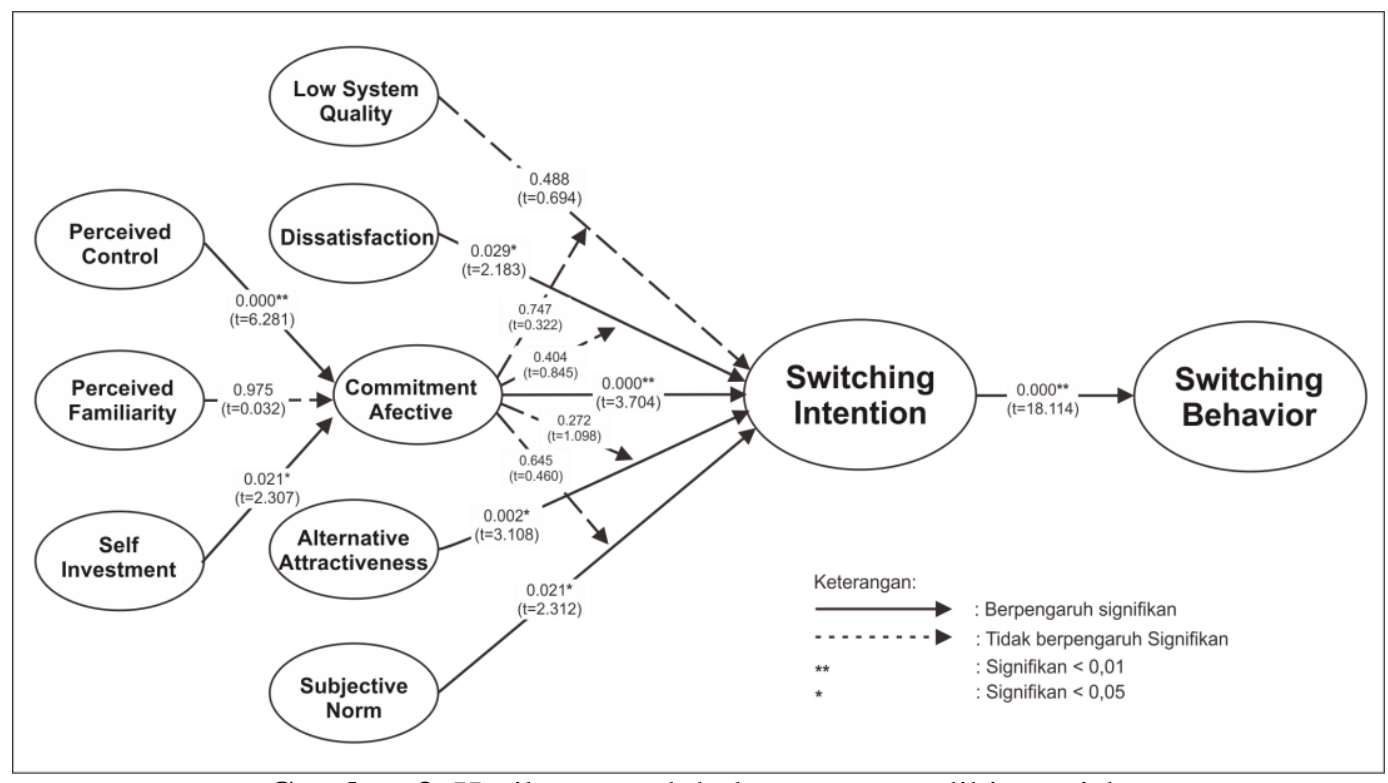

Gambar 3. Hasil pengaruh hubungan yang dihipotesiskan

\subsection{Uji koefisien determinasi $\left(\mathrm{R}^{2}\right)$}

Tahap terakhir adalah melakukan validasi terhadap besarnya pengaruh yang dihasilkan oleh variabel independen terhadap variabel dependennya. Untuk mengetahui besarnya pengaruh tersebut dengan melihat nilai $\mathrm{R}$-square $\left(\mathrm{R}^{2}\right)$. Hasil $\mathrm{R}^{2}$ pada variabel dependen dalam model sebesar $\geq 0.67$ mengidentifikasi bahwa model baik, $\geq 0.33$ moderat dan $\geq 0.19$ mengidentifikasi bahwa model lemah. 
Tabel 5. Hasil R-Square

\begin{tabular}{lrc}
\hline & R Square & Kategori \\
\hline CA & 0.296 & Lemah \\
SB & 0.477 & Moderat \\
SWI & 0.337 & Moderat \\
\hline
\end{tabular}

Berdasarkan Tabel 5 serta memperhatikan model yang dikembangkan, dapat disimpulkan bahwa pengaruh Perceived Control (PC), Perceived Familiarity (PF), dan Self-Investment (SI) terhadap Commitment Affective (CA) memberikan nilai R-square sebesar 0,296 yang dapat diinterpretasikan bahwa variabel Commitment Afective (CA) dapat dijelaskan oleh variabilitas konstruk PC, PF, SI terhadap CA sebesar 29,6\% artinya bahwa 70,4\% dijelaskan oleh variabel lain di luar yang diteliti. Selanjutnya pengaruh Switching Intention (SWI) terhadap Switching Behavior (SB) sebesar 0,477 atau $47,7 \%$ yang berarti bahwa 52,3\% dijelaskan oleh variabel lain di luar yang diteliti, dan pengaruh Commitment Affective (CA) terhadap Switching Intention (SWI) sebesar 0,337 atau $33,7 \%$ dipengaruhi oleh CA, berarti bahwa 66,3\% variabel Switching Intention (SWI) dipengaruhi oleh variabel lain di luar dari yang diteliti. Untuk itu, penelitian selanjutnya diharapkan lebih mengeksplorasi variabel-variabel yang mempengaruhi perilaku beralih MIM di luar dari variabel yang telah diteliti.

\section{Kesimpulan}

Penelitian dilakukan untuk mengetahui pengaruh Push Pull Mooring terhadap perilaku beralih penguna Mobile Instant Messaging (MIM) di Indonesia. Hasil penelitian menjelaskan bahwa variabel yang diajukan sebagai variabel yang mewakili model PPM seperti Dissatisfaction (push factor), Subjective Norm dan Alternative Attractiveness (pull factor) memiliki pengaruh positif terhadap niat beralih dan perilaku beralih pengguna pada aplikasi MIM. Commitment Affective berdampak pada penggunaan aplikasi MIM yang berkelanjutan, sehingga dapat disimpulkan bahwa faktor tersebut dapat dijadikan sebagai indikator dalam meningkatkan loyalitas penggunaan MIM.

Faktor Psychological Ownership (PO) yang terdiri dari Perceived Control dan Self Investment berpengaruh positif terhadap Commitment Affective. Ini berarti bahwa untuk menjaga komitmen terhadap penggunaan MIM, dibutuhkan pemahaman mengenai faktor-faktor yang dapat memunculkan rasa memiliki terhadap objek kepemilikan. Untuk mendorong individu memiliki rasa kepemilikan terhadap aplikasi atau layanan digunakan diperlukan fitur yang dapat meningkatkan perasaan kontrol dan investasi diri sehingga terbangun loyalitas yang berdampak pada penggunaan aplikasi secara berkelanjutan.

\section{Referensi}

[1] Emarketer, "eMarketer Release Latest Estimates for Worldwide Messaging App Usage,” 2017.

[2] A. D. Ahad and S. M. A. Lim, "Convenience or Nuisance?: The 'WhatsApp' Dilemma," Procedia - Soc. Behav. Sci., vol. 155, no. October, pp. 189-196, Nov. 2014.

[3] A. C. Y. Hou, "Switching motivations on instant messaging: A study based on two factor theory," in Communications in Computer and Information Science, 2015.

[4] C. H. Lien and Y. Cao, "Examining WeChat users' motivations, trust, attitudes, and positive word-of-mouth: Evidence from China," Comput. Human Behav., vol. 41, pp. 104-111, 2014.

[5] T. Correa, A. W. Hinsley, and H. G. de Zúñiga, "Who interacts on the Web?: The intersection of users' personality and social media use," Comput. Human Behav., 2010.

[6] T. Zhou and Y. Lu, "Examining mobile instant messaging user loyalty from the perspectives of network externalities and flow experience," Comput. Human Behav., vol. 27, no. 2, pp. 883889, 2011.

[7] A. T. Bhaskoro, "Nielsen: BlackBerry Messenger Masih Jadi Aplikasi Messaging Paling Favorit di Indonesia," 2014. .

[8] JajakPendapat, "Indonesia Messager Trend 2016," 2016. . 
[9] F. Zebua, "Laporan DailySocial: Survey Instant Messaging 2017.," 2017. .

[10] I. C. Chang, C. C. Liu, and K. Chen, "The push, pull and mooring effects in virtual migration for social networking sites," Inf. Syst. J., vol. 24, no. 4, pp. 323-346, 2014.

[11] H. S. Bansal, S. F. Taylor, and Y. S. James, "Migrating' to new service providers: Toward a unifying framework of consumers' switching behaviors," Journal of the Academy of Marketing Science, vol. 33, no. 1. pp. 96-115, 2005.

[12] C. Zengyan, Y. Yinping, and J. Lim, "Cyber migration: An empirical investigation on factors that affect users? Switch intentions in social networking sites," in Proceedings of the 42nd Annual Hawaii International Conference on System Sciences, HICSS, 2009, pp. 1-11.

[13] A. Bhattacherjee and S. C. Park, "Why end-users move to the cloud: A migration-theoretic analysis," Eur. J. Inf. Syst., vol. 23, no. 3, pp. 357-372, 2014.

[14] X. Peng, Y. (Chris) Zhao, and Q. Zhu, "Investigating user switching intention for mobile instant messaging application: Taking WeChat as an example," Comput. Human Behav., vol. 64, pp. 206-216, 2016.

[15] A. Hou, "the Effects of Push-Pull-Mooring on the Switching Model for Social," Pacific Asia Conf. Inf. Syst. 2014 Proc., pp. 1-7, 2014.

[16] A. Madahi and I. Sukati, "An empirical study of Malaysian consumers' channel-switching intention: Using theory of planned behaviour," Glob. Bus. Rev., vol. 17, no. 3, pp. 489-523, 2016.

[17] C. Ye and R. Potter, "The Role of Habit in Post-Adoption Switching of Personal Information Technologies : A Push, Pull and Mooring Model," Inf. Syst., vol. 28, no. 1, pp. 585-610, 2007.

[18] X. Wu, X.-L. Shen, Y. Sun, X. Zhang, S. Chen, and D. Liu, "Understanding users' switching behavior of mobile instant messaging applications: An empirical study from the perspective of push-pull-mooring framework," Comput. Human Behav., vol. 75, pp. 727-738, 2017.

[19] J. L. Pierce, T. Kostova, and K. T. Dirks, "Toward a theory of psychological ownership in organizations," Acad. Manag. Rev., 2001.

[20] Q. Zhao, C. Der Chen, and J. L. Wang, "The effects of psychological ownership and TAM on social media loyalty: An integrated model," Telemat. Informatics, 2016.

[21] G. Sinclair and J. Tinson, "Psychological ownership and music streaming consumption," $J$. Bus. Res., vol. 71, pp. 1-9, Feb. 2017.

[22] J. Cohen, "Statistical Power Analysis," in International Encyclopedia of Education, Elsevier, 1992, pp. 436-443.

[23] A. Willy and J. Hartono, Partial Least Square (PLS) Alternatif Structural Equation Modeling (SEM) dalam Penelitian Bisnis. Yogyakarta: ANDI, 2015.

[24] C. C. Lee, "Sample size estimation using Krejcie and Morgan and Cohen statistical power analysis: A comparison," J. Penyelid. IPBL, 2006.

[25] S. Haryono, Metode SEM untuk Penelitian Manajemen dengan AMOS LISREL PLS. Jakarta: Luxima Metro Media, 2017.

[26] J. K. Hsieh, Y. C. Hsieh, H. C. Chiu, and Y. C. Feng, "Post-adoption switching behavior for online service substitutes: A perspective of the push-pull-mooring framework," Comput. Human Behav., vol. 28, no. 5, pp. 1912-1920, 2012. 